Bunnefeld N, Hoshino E \& Milner-Gulland EJ (2011)

Management strategy evaluation: a powerful tool for conservation? (Opinion), Trends in Ecology and Evolution, 26 (9), pp. 441-447.

This is the peer reviewed version of this article

NOTICE: this is the author's version of a work that was accepted for publication in Trends in Ecology and Evolution. Changes resulting from the publishing process, such as peer review, editing, corrections, structural formatting, and other quality control mechanisms may not be reflected in this document. Changes may have been made to this work since it was submitted for publication. A definitive version was subsequently published in Trends in Ecology and Evolution, [VOL 246 ISS 9 (2011)] DOI:

http://dx.doi.org/10.1016/j.tree.2011.05.003 
1 Management Strategy Evaluation: A powerful tool for conservation?

2 Nils Bunnefeld ${ }^{1}$, Eriko Hoshino ${ }^{1,2}$, Eleanor J. Milner-Gulland ${ }^{1}$

$3{ }^{1}$ Department of Life Sciences, Imperial College London, Silwood Park, Buckhurst Road, 4 Ascot, SL5 7PY, UK

$5 \quad{ }^{2}$ School of Economics and Finance, University of Tasmania, Private Bag 85, Hobart, TAS

67001 , Australia

7 Corresponding author: Bunnefeld, N. (n.bunnefeld06@imperial.ac.uk)

9 The poor management of natural resources has led in many cases to population decline 10 and extirpation. Recent advances in fisheries science have the potential to revolutionize 11 management of harvested stocks by evaluating management scenarios in a virtual world, by including stakeholders, and by assessing its robustness to uncertainty. These advances have been synthesized into a framework, Management Strategy Evaluation

14 (MSE), which has hitherto not been used in terrestrial conservation. We review the 15 potential of MSE to transform terrestrial conservation, emphasizing that the behavior 16 of individual harvesters must be included since harvester compliance with management rules has been a major challenge in conservation. Incorporating resource user decisionmaking required to make MSEs relevant to terrestrial conservation will also advance

19 fisheries science.

\section{Management of natural resources}

22 The management of natural resources is a complex process driven by interactions between 23 the dynamics of the natural system, the decision-making and behavior of stakeholders and 24 uncertainty at various levels of the management process and the natural system. Traditional 25 forms of natural resource management, such as fixed harvest quotas, do not respond to 
1 system dynamics and uncertainty and so are prone to failure [1, 2]. The realization of the

2 importance of learning about the dynamics of the system led to adaptive management [1], in

3 which monitoring of the system allows updating of managers' models of system dynamics,

4 which then produces alterations in the harvest in an iterative process. Adaptive harvest

5 management (AHM) has been successfully applied to ducks, mule deer and sandhill cranes in

6 the USA [3-6].

7

8 Despite the advances made by AHM, harvest management models still do not explicitly

9 incorporate the social processes underlying harvester behavior, and are based on the use of a

10 "best" management solution to achieve a single objective given the current best knowledge.

11 Where the system is relatively simple and harvesters abide by rules, such as in some

12 recreational hunts in the developed world, this may not be problematic. However, in complex

13 systems, with multiple stakeholders and severe uncertainties, it is generally difficult to

14 provide a single best harvest policy [7]. Instead, there is a need to find robust approaches that

15 meet management objectives under a range of potential states of the world [8]. One approach

16 that aims to do this has gained considerable ground within fisheries science, Management

17 strategy evaluation (MSE), uses simulation models within an adaptive framework that

18 enables the comparison of alternative strategies in a virtual world under multiple and often

19 conflicting objectives [9]. In this paper we argue that MSE is a potentially valuable tool for

20 terrestrial conservation if the framework is expanded to include individual harvester decision

21 making.

23 MSE, in common with adaptive management more generally, has four major advantages over

24 standard approaches to providing management advice: (i) It allows experimentation with a

25 range of possible management procedures under a range of circumstances. Real world 
1 experimentation is highly desirable in order to disentangle the drivers of a system, but is

2 difficult to pursue for the majority of natural resources because of the dependence of

3 individuals and firms on resources for their livelihoods and the spatial extent of the systems.

4 In conservation, real world experimentation poses ethical dilemmas: local people often

5 depend on ecosystem services for subsistence, while endangered species may face extinction.

6 (ii) Stakeholders can be directly involved in the development of the management scenarios

7 and the evaluation of the metrics by which the performance of different management options

8 is assessed. A key feature of the MSE approach is that an optimal strategy or solution is not

9 pursued, but instead policies are sought that are feasible, robust to uncertainty and provide

10 adequate management performance with respect to multiple criteria $[9,10]$. This allows for

11 more transparency in the management process and promotes stakeholder acceptance and support. (iii) MSE enables researchers and managers to examine the implications of various forms of uncertainty, including process, measurement and structural uncertainty, on the performance of different management options. (iv) MSE carries out prospective rather than retrospective evaluations of the performance of different management procedures under a range of circumstances. By comparing the performance of a range of alternative strategies under plausible scenarios upfront, the response of the system can be compared to the desired goals and evaluated in advance of implementation (Box 1) [11].

In this paper we start with an explanation how MSE works (Figure 1). We pay special attention to the improvements in management of a real fishery system that MSE has enabled, illustrated with a case study (Box 1). We then outline the role of individual harvester decision-making and socio-economic drivers on management effectiveness, and argue that

24 there is a need to explicitly include this in order to develop the MSE approach further, both

25 for fisheries and for terrestrial conservation. We show how MSE can be applied to terrestrial 
1 conservation using two case studies, brown bear Ursus arctos hunting in Slovenia and

2 Croatia and bushmeat hunting in the Serengeti (Box 2). Finally, we conclude that explicitly

3 including harvester decision-making in the MSE approach increases its realism and opens

4 new horizons to improve the sustainability of harvesting for exploited species.

6 How management strategy evaluation works

7 The MSE approach is based upon a set of models of the "true" population dynamics of the

8 species (called “operating model”; Figure 1, Glossary). The operating model aims at

9 capturing the key processes in the dynamics of the fish population given the best ecological

10 knowledge available and can be thought of as a minimum realistic model [12].

12 The next step in the MSE is to simulate the process of monitoring the stock, resulting in

13 simulated measurements such as biomass or number of individuals. Information from

14 monitoring is always imperfect as it is impossible to detect every single individual or cover

15 the entire area of interest. Monitoring is represented by the "observation model", whereby the

16 statistical features of the collection of relevant data are simulated, including both error and

17 bias.

19 The observation data are then passed to the "management model". The management model

20 encompasses the harvest control rule (HCR) but may also contain an implementation error

21 component. The HCR can be either model based, which includes an assessment of resource status, or an empirical algorithm. The HCR may reference biological or socioeconomic reference points to produce management actions in the form of a harvest or effort level,

24 changes in gear or spatial and temporal restrictions. Management actions are rarely

25 implemented without error. This error can come from two main sources: (i) resource users do 
1 not comply with the regulations, and (ii) the individual dynamics of resource users (e.g. when

2 and where harvest is taken) are not accounted for in the HCR. Neither source of

3 implementation error is generally modeled based on human decision-making in standard

4 MSEs, instead implementation is simulated as a probability distribution around the HCR [13,

5 14]. The full system model therefore contains the operating model (biological "truth"), the

6 observation model, the management model, by which the HCR feeds back into the resource

7 operating model as the model updates to the next time-step (Figure 1).

8

9 By evaluating a range of HCRs against a set of plausible operating models, using multiple

10 performance metrics, MSE enables fisheries scientists to give resource managers advice on

11 robust management procedures (see Glossary), and on the trade-offs involved with each

12 procedure. The learning process can be incorporated into (i) the assessment component of the

13 management procedure when new observations become available; or (ii) the decision process

14 based on a review of the performance of the management strategy. Together with modeling

15 tools such as sensitivity analysis, MSEs can evaluate which data and how much of it should

16 be collected and how often monitoring should be carried out to improve management

17 performance. Stakeholders can be involved at various points in the process of proposing and

18 evaluating different HCRs and assessment approaches. There is ample evidence from both

19 terrestrial conservation and fisheries that stakeholder involvement throughout the process of

20 resource management is key to compromise between stakeholders, acceptance of the rules

21 and hence the sustainability of resource use $[15,16]$.

23 Uncertainty in natural resource management

24 One of the main strengths of MSE is that it brings uncertainty to the centre-stage in the

25 modeling process. Uncertainty plays a fundamental role in the dynamics of ecological and 
1 economic systems, in our measurement and understanding of these systems, and in the

2 devising and implementation of rules to control harvesting. Various classifications exist, and

3 we use that of Milner-Gulland and Rowcliffe [17]: Process uncertainty comes from the

4 variation in the system itself (e.g. weather affecting demographic rates). Measurement

5 (observation) uncertainty occurs in any process of collecting field data and might be due to

6 crude devices or mistakes during measurement. These two forms of uncertainty combine to

7 form parameter uncertainty. Structural uncertainty, also called model uncertainty, has

8 received increased attention in modeling natural resources and represents our lack of

9 understanding of the dynamics of the system [18]. For example, implications of structural

10 uncertainty on whale stocks was examined extensively by the International Whaling

11 Commission [19] and whether hunting mortality is additive or compensatory was

12 incorporated in ducks in the USA [3]. Representing structural uncertainty is generally

13 difficult because a model representing the real system according to our perceptions is only

14 one possible way in which the system could function. Implementation uncertainty surrounds

15 the translation of policy into practice, and has been poorly covered in the natural resource

16 literature, as its causes lie within social science; one example is institutional inertia, another is

17 non-compliance with rules. Because MSE models the entire resource management system,

18 rather than just the resource stock dynamics, it can incorporate all these types of uncertainty

19 and quantify their relative importance.

21 Future directions for natural resource management

22 Including the wider ecosystem

23 Most applications of the MSE approach to date have focused on harvest strategies for target

24 species. The indirect effects of harvesting on the ecosystem are still rarely incorporated into

25 MSEs, but this is changing as fisheries science increasingly takes an ecosystems approach 
1 (e.g. Atlantis model for south-eastern Australia [20, 21]). Multi-species population models

2 and effects on the wider ecosystem have recently been included in an MSE for a prawn

3 fishery in Australia [22, 23]. Similarly, MSEs are now being used to evaluate strategies for

4 limiting bycatch [11] including cetaceans [24].

5

$6 \quad$ More realistic economics

7 Economically-based management has been demonstrated to be better both in terms of the

8 sustainability of the stock and the profitability of fishing [25]. However, many fisheries

9 management plans are still based on outdated concepts of Maximum Sustainable Yield [26].

10 Although more effort is now being directed towards including economics explicitly into

11 MSEs [27, 28], the development of approaches that allow MSEs to incorporate broader social

12 and economic objectives remains an important and urgent area for future research [8]. One

13 fundamental constraint is the lack of reliable economic data, particularly cost data, as the

14 fishing industry is not always willing to release their financial information. Further

15 institutional effort is required to establish a mechanism to collect reliable cost data, such as

16 through strengthening stakeholder involvement and industry collaboration in developing

17 management objectives.

Realistic representation of implementation

20 Hunting and fishing are crucial contributors to people's livelihoods in many parts of the

21 world. Management often works against the short term economic interests of those who

22 depend on resources by decreasing the harvest or closing areas to protect its natural resources. Given the vast areas involved and budgetary constraints, enforcement is generally

24 poor and attempts to control resource use are therefore often ineffectual. The assumption in

25 the vast majority of MSEs that rules are implemented either directly or with simple random 
1 errors is clearly inadequate. Instead, rules affect the resource population indirectly, via the

2 decisions of resource users. Research into factors affecting compliance with conservation

3 rules is starting to blossom [29-31].

5 In commercial fisheries, non-compliance and deviations from set quotas are due to the 6 economic incentives faced by individual fishers; their knowledge of current and past stock 7 status and its spatial distribution have recently been included in MSE models [22, 23, 32, 33].

8 Furthermore, models on the line fishery of the Great Barrier Reef include how individual

9 fishers select reefs, infringe into marine protected areas, and communicate information 10 amongst each other [34, 35].

12 Subsistence or artisanal harvesters operate at the household, rather than the firm level. This means that rather than maximizing profit, the harvester aims to maximize household utility

14 ("satisfaction" or "happiness"). Utility is maximized based upon household consumption of a range of goods, met from production and sale of products derived from livelihood activities such as agriculture, bushmeat hunting or aboriginal subsistence whaling [36, 37]. Models of household utility could be incorporated into an MSE as part of the operating model, representing the "true" state of the harvester component of the system [37-39] (Figure 1). The harvester operating model mediates the effect of management rules on the resource stock, and can also be observed, with uncertainty, by the manager.

22 This enhanced framework allows the inclusion of a wider range of management objectives and performance metrics than standard MSEs; not just the maximization of biological or economic yield and minimization of the risk of population reduction below a threshold, but also maximizing household utility [40]. The welfare of resource users is of key importance in 
1 current conservation thinking, which focuses on the importance of considering human

2 welfare, securing ecosystem service provision and integrating conservation and development.

\section{$4 \quad$ Trade-offs in model complexity}

5 With further advancement of knowledge on ecosystems and species interactions and faster

6 computing power, there is a tendency to increase model complexity. Simple HCRs based on

7 empirical data and threshold rules make management more transparent, faster and less

8 technically challenging to implement and should be integrated within model-based

9 assessments that may more accurately reflect resource stock dynamics [41]. Improving the

10 apparent realism of the management procedure through more complex model structure may

11 not necessarily improve performance [42]. The operating models used in the testing process

12 need to include as much complexity as necessary to adequately capture key dynamics of the

13 system [43]. Including harvest behavior is a key factor in many natural systems and by

14 including this explicitly progress may be made more rapid than by increasing the complexity

15 of the resource operating model. However, performance statistics based on harvester utility

16 should be simple and transparent to ensure stakeholders engagement and understanding.

Technical challenges to MSE application

19 If MSEs are to become widely applied outside fisheries, technical capacity building is

20 required, and theory and models need to become more accessible to less quantitatively

21 orientated researchers. Collaborative software development projects have started to make

22 MSE models more widely available [44], but the inclusion of a harvester operating model

23 would add further difficulty, as these models come from another discipline. Collaboration

24 between natural scientists, economists and sociologists is required to overcome these

25 disciplinary barriers. A freely available suite of methods in the R statistical language, FLR 
1 (Fisheries Library in R [44]), already exists. FLR has a wide array of MSE examples across a

2 range of fishery systems and could be adapted to meet the needs of the wider resource

3 management community.

$5 \quad$ Strengthening links to active adaptive management

6 Active adaptive management (AAM) is a subset of AHM in which managers set out

7 deliberately to learn from the system through experiments and monitoring in a real-world

8 system $[45,46]$. By contrast, in MSE learning is carried out in a virtual world. Since the

9 formulation of the AAM framework, many studies have suggested it could be useful, but

10 seldom have researchers and stakeholders actually implemented the complete framework

11 [47]. Integration of periodic MSEs into the AAM cycle could give added impetus to both,

12 given the great success of the MSE approach in real-life fisheries management [11], and this

13 is already happening in an ad hoc manner in many fisheries.

\section{Limitations of MSE}

16 The management of natural resources is plagued by uncertainty and feedbacks between the

17 dynamics of resources and users. Although MSE goes some way towards addressing these

18 difficulties, it has been criticized for: (i) having a longer development time, and thus

19 increased costs, than traditional methods such as reference-based off-take rules; (ii) an

20 upfront MSE can provide an overly rigid framework without room for decision makers to

21 change management in an adaptive way; and (iii) poor data inputs, such as gaps in monitoring

22 or extremely low estimates of uncertainty, impact the performance of MSE, which needs to

23 be recognized and explored within the MSE process [48-50]. These criticisms point to the

24 need for an iterative process of monitoring, learning and adaptation, which is entirely in 
1 keeping with the MSE approach if practitioners are prepared to engage with the issues being

2 raised.

4 There are barriers to the implementation of MSE in terrestrial conservation, and it is not 5 appropriate to every situation. Hockley et al. [51] show that the effort and costs involved in

6 monitoring crayfish trends are too high for the development of a locally-based monitoring

7 system to be worthwhile which implies the need for more precautionary and risk averse

8 management. Monitoring must have the potential to inform interventions aimed at changing

9 the behavior of resource users (whether these are direct HCRs or other approaches such as

10 alternative livelihoods). If the links in the chain in Figure 1 are non-existent, then a MSE is

11 not feasible; for example in some natural resource user systems, monitoring needed for the

12 observation model or a manager might be missing. In some systems harvesters might abide

13 by the rules set by managers and then a simpler framework would be more parsimonious.

14 Even in these cases, however, an MSE approach would be a useful tool for highlighting the

15 effects of uncertainty on management decision-making.

\section{Conclusions}

18 To date, the only application of a comparable approach to MSE outside fisheries has been by

19 Chee and Wintle [52], for management of over-abundant species. However, the MSE

20 approach has enormous potential for exploited resources that face competing objectives and

21 where harvester decision-making is an important consideration. The MSE approach is no

22 longer limited to top-down management of a single species by an all-powerful manager.

23 Work has already started to extend the MSE approach to more complex systems, to include

24 the ecosystem effects of harvest and to improve the economic realism of the models. Further

25 expansion of the approach to include explicit models of harvester decisions would 
1 dramatically increase the applicability of the approach outside commercial fisheries.

2 However modeling complexity, particularly when models from different disciplines are

3 combined, comes at the cost of potential loss of transparency and the link to reality. Joint

4 efforts to develop tools to handle, visualize and communicate the models underlying MSEs

5 are ongoing [44], and need to be extended to encompass this wider agenda if the full potential

6 of MSE to improve management of natural resource use is to be realized.

7

\section{Box 1}

\section{Example of the successful use of MSE in fisheries}

10 The Southern and Eastern Scalefish and Shark Fishery (SESSF) in Australia is a complex

11 multi-species, multi-gear fishery with 34 stock units managed under a quota system as well as

12 restrictions on gear and input controls implemented based on expert judgment. Despite the

13 introduction of a quota system in 1992, a number of quota-managed species remained

14 overfished. In 2005 a comprehensive harvest strategies framework was introduced and

15 implemented into the SESSF. This framework is similar to a management procedure, where

16 the process of monitoring and assessment is included as well as explicit harvest control rules

17 [41], but at that time, the performance of candidate strategies had not yet been formally evaluated through simulation prior to adoption (such as is done in MSE). Instead, the harvest

19 strategy framework was implemented based on expert judgment and prior experiences of

20 MSE and harvest strategies for other fisheries. The framework involves a "tiered" approach,

21 where 4 different harvest control rules are applied for stocks based on the information

22 available about the stocks and the levels of uncertainties involved in their stock assessments.

23 For example, a stock is classified as tier 1 if there is a "robust" quantitative assessment, and

24 tier 2 if it has a less certain or preliminary assessment. From 2006, a full MSE was

25 conducted, including formal evaluation of harvest strategies. In 2008, Smith et al. [11] 
1 evaluated the lessons learnt from this fishery concerning the benefits of a harvest strategy

2 framework compared to conventional fisheries management. Since the introduction of the

3 framework in 2005, there has been an overall net decrease in the total quota level set for the

4 fishery, with concomitant conservation benefits, but also a more favorable response to

5 science-based policy recommendations from both industry and managers due to the well-

6 specified and adopted decision rules. This is testified to by the fact that the time and effort

7 taken to reach agreement on the total allowable catch (TAC) limits each year has significantly

8 reduced, from several weeks to less than two days. The general lessons learnt from this case

9 study include the importance of formally testing management options using MSE prior to

10 implementation, rather than post-hoc, the difficulty in defining rules to deal with bycatch

11 TACs for this multi-species and multi-fleet fishery, and the need for flexible and pragmatic

12 implementation by managers [11].

\section{Box 2}

\section{The potential for MSE in conservation}

16 A recent workshop highlighted examples where an MSE approach would shed new light on

17 the issues surrounding the management of harvested terrestrial systems [53]. The first example considers the management of the brown bear (Ursus arctos) in Croatia and Slovenia [54] (Figure 1 within Box 2). Traditionally, the brown bear was hunted as a trophy species in

20 both countries but since Slovenia entered the EU in 2004 the species is protected under EU

21 law. Slovenian bears are now culled to control population size. With their neighboring non-

22 EU country Croatia continuing to manage bears as a trophy species, two contrasting systems

23 are currently managing the same population. The MSE approach could contribute to a

24 cooperative approach between the two countries by demonstrating the potential benefits of a

25 joint monitoring and management decision framework. Collaborative monitoring could 
1 potentially reduce uncertainty in the estimated total population size, allowing more informed

2 quota-setting. Furthermore, the incentives of hunters differ between the two countries based

3 on their hunting regimes. Finally, manager decision-making is strongly dependent on social

4 and political conditions in the two countries, and these social issues as well as hunter

5 decision-making need to be incorporated in the development of scenarios for the management

6 of this population.

7

8 The second example comes from bushmeat hunting in Tanzania which is in theory state-

9 controlled by licenses and quotas (Figure 2 within Box 2) [55, 56]. However, non-compliance

10 is high and hard to quantify because hunting is dispersed and heterogeneous both spatially

11 and temporally, and in terms of catch compositions. For the sustainable management of such

12 a system it is crucial to understand the incentives of local people who hunt. The current

13 management system faces high uncertainties due to a lack of governance and control, such

14 that the system is effectively open access hunting for an illegal good. There is also no benefit

15 distribution to act as an incentive not to hunt bushmeat. This case study is an excellent

16 example of a linked social-ecological system, where MSE could be used to explore feedbacks

17 between conservation incentives and livelihood decisions (Figure 1). Instead of focusing on

18 testing just the performance of HCRs, the MSE approach can be adapted to investigate the

19 effectiveness of a range of other conservation policies through their effects on hunter's

20 decision-making (for example providing alternative livelihoods or direct payments for

21 conservation services).

23 Acknowledgements

24 NB and EJMG were supported by the European Commission under the HUNT project of the

$257^{\text {th }}$ Framework Programme for Research and Technological Development. Neither the 
1 European Commission nor any person acting on behalf of the Commission is responsible for

2 the use made of the information. The views expressed in this publication are the sole

3 responsibility of the authors and do not necessarily reflect the views of the European

4 Commission. EJMG also acknowledges the support of a Royal Society Wolfson Research

5 Merit award, and thanks Franck Courchamp and the Department of Ecology, Systematics and

6 Evolution at the Université Paris Sud for hosting EJMG during working on this paper. We

7 thank Justin Irvine, Emily Nicholson, Ana Nuno and Lynsey McInnes, Charles Edwards,

8 Julia Blanchard, Andre Punt and two anonymous referees for invaluable comments.

10 Figure 1: Flow diagram for the Management Strategy Evaluation framework comprising a

11 resource operating model (simulating the "true" population biology of the species), the

12 observation model to monitor the species (with error) and the management model, using the

13 perceived stock to create and implement the harvest control rules. In the extended model

14 (dotted line) the harvest control rule is fed into an additional harvester model which allows

15 for individual decision-making by harvesters. In this model, the harvester can also be

16 monitored through the observation model (dotted line).

18 Glossary

19 Assessment model: A mathematical model coupled to a statistical estimation process that

20 integrates data from a variety of sources to provide estimates of reference points and past and 21 present abundance, mortality, and productivity of a resource.

22 Harvest control rule (HCR): A set of well-defined rules used for determining management

23 actions in the form of a total allowable catch $(T A C)$ or allowable effort.

24 Harvest strategy: Intended meaning may be synonymous with $M P$. 
1 Implementation model: The process of application of the management action, including the

2 uncertainty involved in the process.

3 Management model: A model of the process of management, which encompasses the

4 harvest control rule (HCR) and may also contain implementation error.

5 Management procedure (MP): The process of using monitoring data and a formula or

6 model to generate $T A C$ or effort control measure.

7 Management strategy evaluation (MSE): The process of testing the performance of generic

$8 M P s$ or harvest strategies against predefined metrics such as mean and variance in yield.

9 Management strategy: Usually synonymous with $M P$ but sometimes used to mean an $H C R$.

10 Observation model: The component of the $O M$ that generates simulated monitoring data

11 from observation of the dynamics of the natural resource stock, for input into an $M P$.

12 Operating model (OM): A mathematical-statistical model used to describe the true state of

13 the system in terms of (i) the natural resource dynamics and (ii) the harvester behavior.

14 Total allowable catch (TAC): Catch limit to be taken from a resource within a specified

15 period.

16 Utility: Measure of relative satisfaction or happiness from consumptive and monetary goods

17 (e.g. amount of harvest) and non-monetary goods (e.g. leisure time, satisfaction from

18 recreational hunting).

\section{Figure 1 within Box 2}

21 Brown bear (Ursus arctos) management in Slovenia and Croatia as a case study in terrestrial

22 conservation where a Management Strategy Evaluation approach could give new insights.

23 Photo by Miha Krofel. 


\section{Figure 2 within Box 2}

2 A case study for the potential of the Management Strategy Evaluation in conservation:

3 bushmeat hunting in Tanzania. Examples of species hunted for bushmeat: a) zebra (Equus quagga); b) buffalo (Syncerus caffer), c) impala (Aepyceros melampus) and d) blue wildebeest (Connochaetes taurinus) [57, 58].

\section{References}

1 Walters, C.J. and Hilborn, R. (1976) Adaptive control of fishing systems. J Fish Res Board Can 33, 145-159

2 Packer, C., et al. (2009) Sport hunting, predator control and conservation of large carnivores. PLoS One 4, e5941

3 Runge, M.C., et al. (2002) A revised protocol for the adaptive harvest management of midcontinent mallards. In U.S. Department of the Interior Technical report, Fish and Wildlife Service

4 Nichols, J.D., et al. (2007) Adaptive harvest management of North American waterfowl populations: a brief history and future prospects. J Ornithol 148, S343-S349

5 Kendall, W.L. and Drewien, R.C. (2001) Models for the adaptive harvest management of Rocky Mountain sandhill cranes: problems and potential In Proceedings of the Eighth North American Crane Workshop, pp. 217

6 Mason, R., et al. (2006) A case for standardized ungulate surveys and data management in the western United States. Wildlife Soc B 34, 1238-1242

7 Nicholson, E. and Possingham, H.P. (2007) Making conservation decisions under uncertainty for the persistence of multiple species. Ecol Appl 17, 251-265

8 Mapstone, B.D., et al. (2008) Management strategy evaluation for line fishing in the Great Barrier Reef: Balancing conservation and multi-sector fishery objectives. Fish Res 94, 315329

9 Smith, A.D.M., et al. (1999) Implementing effective fisheries-management systems management strategy evaluation and the Australian partnership approach. Ices J Mar Sci 56, 967-979

10 Cooke, J.G. (1999) Improvement of fishery-management advice through simulation testing of harvest algorithms. Ices J Mar Sci 56, 797-810

11 Smith, A.D.M., et al. (2008) Experience in implementing harvest strategies in Australia's south-eastern fisheries. Fish Res 94, 373-379

12 Punt, A.E. and Butterworth, D.S. (1995) The effects of future consumption by the Cape fur seal on catches and catch rates of the cape hakes. 4. Modelling the biological interaction between Cape fur seals Arctocephalus pusillus pusillus and the cape hakes Merluccius capensis and M-paradoxus. S Afr J Marine Sci 16, 255-285

13 Needle, C.L. (2008) Management strategy evaluation for North Sea haddock. Fish Res 94, 141-150

14 Fulton, E.A., et al. (2011) Human behaviour: the key source of uncertainty in fisheries management. Fish Fish 12, 2-17 
15 Cochrane, K.L., et al. (1998) Management procedures in a fishery based on highly variable stocks and with conflicting objectives: Experiences in the South African pelagic fishery. Rev Fish Biol Fisher 8, 177-214

16 Waylen, K.A., et al. (2010) Effect of local cultural context on the success of communitybased conservation interventions. Conserv Biol 24, 1119-1129

17 Milner-Gulland, E.J. and Rowcliffe, M.J. (2007) Wildlife Conservation and Sustainable Use: A handbook of techniques. Oxford University Press

18 Hill, S.L., et al. (2007) Model uncertainty in the ecosystem approach to fisheries. Fish Fish 8, 315-336

19 IWC (2010) The Annual Report of the International Whaling Commission The International Whaling Commission

20 Fulton, E.A., et al. (2004) Biogeochemical marine ecosystem models I: IGBEM - a model of marine bay ecosystems. Ecol Model 174, 267-307

21 Smith, A.D.M., et al. (2007) Scientific tools to support the practical implementation of ecosystem-based fisheries management. Ices J Mar Sci 64, 633-639

22 Dichmont, C.M., et al. (2008) Beyond biological performance measures in management strategy evaluation: Bringing in economics and the effects of trawling on the benthos. Fish Res 94, 238-250

23 Dichmont, C.M., et al. (2010) On implementing maximum economic yield in commercial fisheries. P Natl Acad Sci USA 107, 16-21

24 Punt, A.E. and Donovan, G.P. (2007) Developing management procedures that are robust to uncertainty: lessons from the International Whaling Commission. Ices J Mar Sci 64, 603612

25 Grafton, R.Q., et al. (2007) Economics of overexploitation revisited. Science 318, 16011601

26 EU (2006) Implementing sustainability in EU fisheries through maximum sustainable yield In Communication from the Commission to the Council and the European Parliament COM 360, Commission of the European Communities

27 Maravelias, C.D., et al. (2010) Stochastic bioeconomic modelling of alternative management measures for anchovy in the Mediterranean Sea. Ices J Mar Sci 67, 1291-1300 28 Hoshino, E., et al. (2010) Economically optimal management strategies for the South Georgia Patagonian Toothfish Fishery. Mar Resour Econ 25, 265-280

29 Keane, A., et al. (2008) The sleeping policeman: understanding issues of enforcement and compliance in conservation. Anim Conserv 11, 75-82

30 John, F.A.V.S., et al. (2010) Testing novel methods for assessing rule breaking in conservation. Biol Conserv 143, 1025-1030

31 Gavin, M.C., et al. (2010) Measuring and monitoring illegal use of natural resources. Conserv Biol 24, 89-100

32 Agnew, D.J., et al. (2009) Estimating the worldwide extent of illegal fishing. PLoS One 4 33 van Oostenbrugge, H.J.A.E., et al. (2008) Linking catchability and fisher behaviour under effort management. Aquat Living Resour 21, 265-273

34 Little, L.R., et al. (2005) Effects of size and fragmentation of marine reserves and fisher infringement on the catch and biomass of coral trout, Plectropomus leopardus, on the Great Barrier Reef, Australia. Fisheries Manag Ecol 12, 177-188

35 Little, L.R., et al. (2009) An agent-based model for simulating trading of multi-species fisheries quota. Ecol Model 220, 3404-3412

36 Tillman, M.F. (2008) The International Management of Aboriginal Whaling. Rev Fish Sci $16,437-444$ 
37 Barrett, C.B. and Arcese, P. (1998) Wildlife harvest in integrated conservation and development projects: Linking harvest to household demand, agricultural production, and environmental shocks in the Serengeti. Land Econ 74, 449-465

38 Damania, R., et al. (2005) A bioeconomic analysis of bushmeat hunting. P Roy Soc B-Biol Sci 272, 259-266

39 Winkler, R. Why do ICDPs fail?: The relationship between agriculture, hunting and ecotourism in wildlife conservation. Resource and Energy Economics

40 Milner-Gulland, E.J. (2011) Integrating fisheries approaches and household utility models for improved resource management. P Natl Acad Sci USA 108, 1741-1746

1041 Rademeyer, R.A., et al. (2007) Tips and tricks in designing management procedures. Ices

11 JMar Sci 64, 618-625

1242 Walters, C.J. (1985) Bias in the estimation of functional relationships from time-series

13 data. Can J Fish Aquat Sci 42, 147-149

1443 Fulton, E.A., et al. (2004) Biogeochemical marine ecosystem models II: the effect of 44 Kell, L.T., et al. (2007) FLR: an open-source framework for the evaluation and development of management strategies. Ices J Mar Sci 64, 640-646

45 Sainsbury, K.J., et al. (2000) Design of operational management strategies for achieving fishery ecosystem objectives. Ices J Mar Sci 57, 731-741

46 Hauser, C.E. and Possingham, H.P. (2008) Experimental or precautionary? Adaptive management over a range of time horizons. $J$ Appl Ecol 45, 72-81

47 Walters, C.J. (2007) Is adaptive management helping to solve fisheries problems? Ambio 36, 304-307

48 Butterworth, D.S. (2007) Why a management procedure approach? Some positives and negatives. Ices J Mar Sci 64, 613-617

49 Rochet, M.J. and Rice, J.C. (2009) Simulation-based management strategy evaluation: ignorance disguised as mathematics? Ices J Mar Sci 66, 754-762

50 Butterworth, D.S., et al. (2010) Purported flaws in management strategy evaluation: basic problems or misinterpretations? Ices J Mar Sci 67, 567-574

51 Hockley, N.J., et al. (2005) When should communities and conservationists monitor exploited resources? Biodivers Conserv 14, 2795-2806

52 Chee, Y.E. and Wintle, B.A. (2010) Linking modelling, monitoring and management: an integrated approach to controlling overabundant wildlife. J Appl Ecol 47, 1169-1178

53 Milner-Gulland, E.J., et al. (2010) New directions in management strategy evaluation through cross-fertilization between fisheries science and terrestrial conservation. Biol Letters $6,719-722$

54 Zedrosser, A., et al. (2001) Status and management of the brown bear in Europe. Ursus $12,9-20$

55 Loibooki, M., et al. (2002) Bushmeat hunting by communities adjacent to the Serengeti National Park, Tanzania: the importance of livestock ownership and alternative sources of protein and income. Environmental Conservation 29, 391-398

56 Sinclair, A.R.E. (2008) Historical and future changes to the Serengeti ecosystem. In Serengeti III: Human Impacts on Ecosystem Dynamics (Sinclair, A.R.E. and Packer, C., eds), pp. 7-46, University of Chicago Press

57 Metzger, K.L., et al. (2010) Evaluating the protection of wildlife in parks: the case of African buffalo in Serengeti. Biodivers Conserv 19, 3431-3444

58 Campbell, K. and Hofer, H. (1995) People and wildlife: spatial dynamics and zones of interaction. In Serengeti II: dynamics, management, and conservation of an ecosystem (Sinclair, A.R.E. and Arcese, P., eds), pp. 534-570, Chicago University Press 